\title{
Mesenchymal stromal cell-derived exosomes ameliorate peripheral neuropathy in a mouse model of diabetes
}

\author{
Baoyan Fan ${ }^{1} \cdot$ Chao $^{\mathrm{Li}^{1}} \cdot$ Alexandra Szalad ${ }^{1} \cdot$ Lei Wang ${ }^{1} \cdot$ Wanlong Pan ${ }^{1} \cdot$ Ruilan Zhang ${ }^{1} \cdot$ Michael Chopp ${ }^{1,2}$. \\ Zheng Gang Zhang ${ }^{1} \cdot$ Xian Shuang Liu ${ }^{1}$
}

Received: 11 June 2019 / Accepted: 9 October 2019/Published online: 19 November 2019

(C) Springer-Verlag GmbH Germany, part of Springer Nature 2019

\begin{abstract}
Aims/hypothesis Diabetic peripheral neuropathy (DPN) is one of the major complications of diabetes, which contributes greatly to morbidity and mortality. There is currently no effective treatment for this disease. Exosomes are cell-derived nanovesicles and play an important role in intercellular communications. The present study investigated whether mesenchymal stromal cell (MSC)-derived exosomes improve neurological outcomes of DPN.

Methods Exosomes were isolated from the medium of cultured mouse MSCs by ultracentrifugation. Diabetic mice (BKS.Cg$\left.m+/+\operatorname{Lepr}^{d b} / J, d b / d b\right)$ at the age of 20 weeks were used as DPN models. Heterozygous mice $(\mathrm{db} / \mathrm{m})$ of the same age were used as the control. MSC-exosomes were administered weekly via the tail vein for 8 weeks. Neurological function was evaluated by testing motor and sensory nerve conduction velocities, and thermal and mechanical sensitivity. Morphometric analysis was performed by myelin sheath staining and immunohistochemistry. Macrophage markers and circulating cytokines were measured by western blot and ELISA. MicroRNA (miRNA) array and bioinformatics analyses were performed to examine the exosomal miRNA profile and miRNA putative target genes involved in DPN.

Results Treatment of DPN with MSC-exosomes markedly decreased the threshold for thermal and mechanical stimuli and increased nerve conduction velocity in diabetic mice. Histopathological analysis showed that MSC-exosomes markedly augmented the density of FITC-dextran perfused blood vessels and increased the number of intraepidermal nerve fibres (IENFs), myelin thickness and axonal diameters of sciatic nerves. Western blot analysis revealed that MSC-exosome treatment decreased and increased M1 and M2 macrophage phenotype markers, respectively. Moreover, MSC-exosomes substantially suppressed proinflammatory cytokines. Bioinformatics analysis revealed that MSC-exosomes contained abundant miRNAs that target the Toll-like receptor (TLR)4/NF-KB signalling pathway.

Conclusions/interpretation MSC-derived exosomes alleviate neurovascular dysfunction and improve functional recovery in mice with DPN by suppression of proinflammatory genes.
\end{abstract}

Keywords Diabetes $\cdot$ Diabetic peripheral neuropathy $\cdot$ Exosomes $\cdot$ Inflammation $\cdot$ Mesenchymal stromal cells $\cdot$ miRNA

Abbreviations
BCA
DPN

Bicinchoninic acid

Diabetic peripheral neuropathy

Electronic supplementary material The online version of this article (https://doi.org/10.1007/s00125-019-05043-0) contains supplementary material, which is available to authorized users.

Xian Shuang Liu

xliu2@hfhs.org

1 Department of Neurology, Henry Ford Health System, 2799 West Grand Boulevard, Detroit, MI 48202, USA

2 Department of Physics, Oakland University, Rochester, MI, USA

$\begin{array}{ll}\text { GSK } & \text { Glycogen synthase kinase } \\ \text { IENF } & \text { Intraepidermal nerve fibre } \\ \text { iNOS } & \text { Inducible nitric oxide synthase } \\ \text { IPA } & \text { Ingenuity Pathway Analysis } \\ \text { IRAK1 } & \text { Interleukin-1 receptor-associated kinase 1 } \\ \text { MBP } & \text { Myelin basic protein } \\ \text { MCV } & \text { Motor nerve conduction velocity } \\ \text { miRNA } & \text { MicroRNA } \\ \text { MSC } & \text { Mesenchymal stromal cell } \\ \text { MSC-exosomes } & \text { MSC-derived exosomes } \\ \text { PGP9.5 } & \text { Protein gene product 9.5 } \\ \text { PU } & \text { Perfusion units } \\ \text { ROI } & \text { Region of interest }\end{array}$




\section{Research in context}

\section{What is already known about this subject?}

- The development and progression of diabetic peripheral neuropathy (DPN) correlates closely with neuroinflammation and marked neurovascular abnormalities in the distal nerves

- Mesenchymal stromal cells (MSCs) have been reported to ameliorate DPN

What is the key question?

- Do MSC-derived exosomes have therapeutic effects on DPN?

What are the new findings?

- MSC-exosomes alleviate neurovascular dysfunction and axonal demyelination and improve neurological outcomes

- $\quad$ MSC-exosomes reduce the inflammatory response in the circulation and peripheral nerves

How might this impact on clinical practice in the foreseeable future?

- Our findings provide new evidence supporting the further investigation of MSC-exosomes as a possible treatment for patients with DPN

SCV

TLR

Sensory nerve conduction velocity

Toll-like receptor

\section{Introduction}

Diabetic peripheral neuropathy (DPN) is one of the most prevalent chronic complications of diabetes mellitus [1]. It is estimated that, by the year 2030, 50 million people worldwide will develop this disease [2]. There is a compelling need to develop effective therapies specifically designed to improve neurological function in the damaged peripheral nervous system that results from diabetes. The reduction of DPN has previously mainly focused on blood glucose control; however, clinical studies of type 2 diabetes have revealed that glucose control has little or no effect in alleviating DPN [3]. Studies in patients and animal models of DPN suggest a relationship between vasa nervorum endothelium and neuropathy $[4,5]$. Perfusion deficit leads to endoneurial hypoxia that compromises nerve function and triggers the process of neurodegeneration [6, 7]. Accordingly, targeting neurovascular dysfunction may reduce DPN.

Upregulation of immune molecules is observed during the early stages of DPN and persists during all stages of the disease [8]. Hyperglycaemia coupled with dislipidaemia triggers the production of adhesion molecules, cytokines and inflammatory genes from immune cells and adipocytes and chronic inflammation contributes to neurovascular damage including axonal degeneration, endothelial dysfunction and metabolic disruption of Schwann cells $[6,9]$. Activation of the NF- $\mathrm{KB}$ pathway is one of the common downstream mechanisms of inflammation in diabetic neuropathy, and leads to the recruitment of immune cells and neuronal dysfunction by triggering a cascade of proinflammatory cytokines and chemokine production $[10,11]$.

Mesenchymal stromal cells (MSCs) have been widely considered as a promising cell therapy for the treatment of neurological disorders [12, 13]. MSCs facilitate peripheral neuropathy repair primarily via paracrine effects and their secretion of angiogenic and neurotrophic factors, and antiinflammatory molecules [14-16]. However, MSC transplantation as a therapy is compromised by a long induction period and potential tumour formation $[17,18]$. Exosomes are endosomalorigin membranous nanovesicles with a diameter ranging from approximately $50 \mathrm{~nm}$ to $100 \mathrm{~nm}$ [19]. Exosomes contain functional mRNAs, microRNAs (miRNAs), proteins and lipids [20]. Exosomes are produced by most cell types and play a pivotal role in cell-to-cell communication by acting as biological transporters. They also have low immunogenicity and the ability to cross the blood-brain barrier [20,21]. The therapeutic effect of MSC-derived exosomes (MSC-exosomes) has been demonstrated in preclinical studies of cancer and brain and cardiovascular diseases [20, 22]. However, whether MSC-exosomes have a therapeutic effect on DPN remains unexplored.

In the present study, we tested the hypothesis that MSCexosomes contribute to anti-inflammatory effects and improve functional recovery in mice with DPN.

\section{Methods}

Exosome isolation and quantification Mouse bone marrowderived MSCs (BM-MSCs) were purchased from Thermo 
Fisher Scientific (Waltham, MA, USA) and cultured with DMEM/F-12 medium containing 5\% exosome-depleted FBS (Thermo Fisher Scientific). Every other day, the supernatant of cultured MSCs was collected and centrifuged at $2000 \mathrm{~g}$ for $10 \mathrm{~min}$ at $4^{\circ} \mathrm{C}$ followed by $10,000 \mathrm{~g}$ for $30 \mathrm{~min}$ at $4^{\circ} \mathrm{C}$ to discard cells, membranes and debris, and then filtered through $0.22 \mu \mathrm{m}$ filters. Exosome isolation was performed via ultracentrifugation at $100,000 \mathrm{~g}$ for $2 \mathrm{~h}$ at $4^{\circ} \mathrm{C}$ [23]. The exosomes in the pellet were verified by transmission electron microscopy (TEM) and western blot detection of common exosome marker proteins. Quantity and size distribution of exosomes were measured using the Nanosight system (NS300, Cambridge, UK).

Animals All experimental procedures were carried out in accordance with the NIH Guide for the Care and Use of Laboratory Animals and approved by the Institutional Animal Care and Use Committee (IACUC) of Henry Ford Hospital. Twentyweek-old male BKS.Cg- $m+/+L e p r^{d b} / J(d b / d b)$ mice (Jackson Laboratories, Bar Harbor, ME, USA) were used. Heterozygous mice $(d b / \mathrm{m})$, a non-penetrant genotype (Jackson Laboratories), of the same age, were used as the control groups. $d b / d b$ mice were randomly divided into two groups according to a randomisation scheme: saline $(0.9 \% \mathrm{NaCl})(d b / d b)$, and MSC-exosomes ( $d b+$ exo) ( $n=8$ per group). Blood glucose, $\mathrm{HbA}_{1 \mathrm{c}}$, total cholesterol and triacylglycerol levels were tested every 2 weeks. MSC-exosomes $\left(1 \times 10^{9}\right.$ particles per animal per injection) were administered via a tail vein weekly for 8 consecutive weeks. Functional tests were performed every 2 weeks as indicated in Fig. 2a. All animals were euthanised at week 8 after the initial treatment and tissues were collected for further analysis. Experimenters were not blind to group assignment and outcome assessment, and no mouse was excluded from the experiments.

Labelling of exosomes To track the in vivo distribution, MSCexosomes were transfected using Texas-red labelled RNA oligonucleotides using Exo-Fect exosome transfection kit (System Bioscience, Palo Alto, CA, USA). Two $d b / d b$ mice were given a one-time injection of labelled MSC-exosomes via a tail vein $\left(1 \times 10^{9}\right.$ particles/animal). Twenty-four hours later, sciatic nerve and footpad tissues were collected, fixed, and cut into $6 \mu \mathrm{m}$ paraffin sections.

Neurophysiological measurements Sciatic nerve conduction velocity was examined every 4 weeks using orthodromic recording techniques. Mice were anaesthetised with $1.5 \%$ isoflurane and electrodes were placed at the knee and sciatic notch. An isolated pulse stimulator (Model 2100, A-M Systems, Sequim, WA, USA) delivered triggered single square wave current pulses to those areas. Simultaneous electromyography was recorded in the dorsum of the foot. Motor nerve conduction velocity (MCV) and sensory nerve conduction velocity (SCV) were calculated according to a published study [24].

Measurement of thermal and mechanical sensitivity To examine the sensitivity of the mice to heat, a plantar test was performed using a thermal stimulation meter (IITC Life Science, Woodland Hills, CA, USA) according to published methods [25]. Mice were acclimated on a transparent glass surface for at least $20 \mathrm{~min}$. To test thermal sensitivity, the stimulator was placed beneath the plantar surface of the hind paw or tail tip. The withdrawal latency in response to the radiant heat (15\% heating intensity) was recorded. Three readings per animal were taken at $15 \mathrm{~min}$ intervals, and the mean reading per mouse was calculated.

To examine tactile allodynia, von Frey filaments (Stoelting, Wood Dale, IL, USA) with forces ranging from 0.02 to $1.4 \mathrm{~g}$ were used to stimulate paw withdrawal. The withdrawal in response to each stimulus was recorded and a 50\% paw withdrawal threshold was calculated according to the published formula [26].

Vasa nervorum blood flow A laser Doppler perfusion imager system (PeriCam PSI System, Perimed, Datavägen, Sweden) was used to examine blood perfusion in plantar skin and sciatic nerve [25]. Mice were anaesthetised and both sciatic nerves were exposed. The sensor was placed $10 \mathrm{~cm}$ above the region of interest (ROI). The image-capturing parameters were set up as follows: the point density was set as high, the frame rate was 21 images per second, and the effective frame rate was 0.8 images/s. The perfusion colour scale was adjusted as $0-300$ for plantar skin and $0-50$ for sciatic nerve. The value of the intensity filter was set as $0.27-10$. The perfusion units (PU) in selected ROIs were recorded; mean perfusion values were calculated within a period of $1 \mathrm{~min}$. Animal rectal temperature was maintained at $37 \pm 1.0^{\circ} \mathrm{C}$ with a feedback-controlled water bath during the measurement period.

FITC-dextran (molecular mass $2000 \mathrm{kDa}, 500 \mathrm{mg} / \mathrm{kg}$, Sigma-Aldrich, St Louis, MO, USA) was injected intravenously $15 \mathrm{~min}$ before death. Sciatic nerves were removed and fixed in $4 \%$ paraformaldehyde for $2 \mathrm{~h}$. Whole nerves were mounted and observed under a $\times 10$ microscope objective using a laser scanning confocal microscope (Zeiss LSM 510 NLO, Carl Zeiss Oberkochen, Germany).

Myelin sheath staining The sciatic nerves were fixed in 2.5\% glutaraldehyde and $0.5 \%$ sucrose in PBS buffer for $6-8 \mathrm{~h}$, and then immersed in $2 \%$ osmium tetroxide for $2 \mathrm{~h}$. The nerve tissue was then dehydrated through alcohol passages and embedded in paraffin. Transverse sections $2 \mu \mathrm{m}$ thick were cut and stained with $1 \%$ toluidine blue. Light microscopic images from toluidine blue-stained sections were acquired via oil immersion objective $(\times 100$, BX40; Olympus Optical, Tokyo, Japan) and morphometric analysis was performed by 
means of the MicroComputer Imaging Device imaging system (MCID, Molecular Devices, Sunnyvale, CA, USA). Fibre density, myelinated fibre diameter, axon diameter, and myelin sheath thickness were measured for each fibre $(>300$ fibres in each group). The $g$-ratio (the quotient axon diameter:fibre diameter) was calculated to measure the degree of myelination.

Immunohistochemistry Tissue samples were fixed in 4\% paraformaldehyde and embedded in paraffin, then cut into sections ( $6 \mu \mathrm{m}$ thick). One section was chosen from every ten sections for a total of three cross-sections per animal, which were used for immunostaining. The primary antibodies used were protein gene product 9.5 (PGP9.5, 1:1000; AB1761-I, MilliporeSigma, Burlington, MA, USA), myelin basic protein (MBP, 1:200; ab40390, Abcam, Cambridge, MA, USA), hypophosphorylated neurofilament H (NF200, 1:100; ab8135, Abcam), normal rabbit IgG (1:300, ab172730, Abcam) was used as a negative control. All primary antibodies were diluted in 3\% BSA in PBS. Sections were counterstained with DAPI (1:5000, D1306, Thermo Fisher Scientific).

For subcutaneous innervations, every PGP9.5-positive nerve fibre in the dermis within a $50 \mu \mathrm{m}$ radius from the epidermal/dermal junction was measured, and the number of PGP9.5-immunoreactive nerve fibres with a cross-sectional area of $\leq 20 \mu \mathrm{m}^{2}$ was counted. Data are presented as nerve fibre density calculated based on a published formula [25].

Isolation and treatment of intraperitoneal macrophages Twenty-week-old $d b / \mathrm{m}$ and $d b / d b$ mice were anaesthetised using $2 \%$ isoflurane. Macrophages were elicited by intraperitoneal injection of PBS containing $5 \mathrm{mmol} / \mathrm{l}$ EDTA. Cells were seeded in 24 well plates at $10^{5}$ cells/well and cultured in RPMI1640 (Gibco, Thermo Fisher Scientific) supplemented with 10\% FBS (Gibco) [27]. To test the direct effect of MSCexosomes on macrophage polarisation, cells were treated with/without exosomes at a dose of $10^{8}$ or $10^{9}$ particles/well for $48 \mathrm{~h}$. Macrophages were collected for further analysis.

Measurement of pancreatic insulin content Pancreases were homogenised in $0.2 \mathrm{~mol} / 1 \mathrm{HCL}$ (in $75 \%$ ethanol) and incubated overnight at $4^{\circ} \mathrm{C}$. Insulin in the supernatant was tested using mouse ELISA kit (Thermo Fisher Scientific). Total protein content was tested in the same sample using bicinchoninic acid (BCA) protein assay (Thermo Fisher Scientific). The insulin content was expressed as $\mu \mathrm{g} / \mathrm{mg}$ protein.

Western blotting and ELISA Samples were lysed with RIPA buffer and centrifuged for $10 \mathrm{~min}$ at 12,000 $\mathrm{g}$ to remove cell debris. BCA assay (Thermo Fisher Scientific) was used to determine the protein concentrations. Equal amounts of proteins were then separated by SDS-PAGE and transferred to a nitrocellulose membrane, which was probed with the appropriate primary antibody and secondary antibodies conjugated to horseradish peroxidase (1:2000, ab97040, ab6940, Abcam, in PBST). The following antibodies were used: $\beta$ actin (1:5000, ab6276, Abcam), CD9 (1:500, ab92726, Abcam), CD63 (1:500, ab34045, Abcam), Alix (1:500, 2171, Cell Signaling Technology, Danvers, MA, USA), interleukin-1 receptor-associated kinase 1 (IRAK1; 1:1000, SC-7883, Santa Cruz, Dallas, TX, USA), arginase-1 (1:200, SC-18351, Santa Cruz), TNF- $\alpha$ (1:200, 250,844, Abbiotec, San Diego, CA, USA), inducible nitric oxide synthase (iNOS; 1:500, ABN26, MilliporeSigma), IL-1 $\beta$ (1:500, ab9787, Abcam), IL-10 (1:1000, ab9969, Abcam), TGF- $\beta$ (1:500, ab31013, Abcam), Toll-like receptor (TLR)4 (1:200, SC-10741, Santa Cruz), NF-kB p65 (1:1000, ab7970, Abcam), insulin receptor substrate 1 (IRS-1; 1:1000, 2382, Cell Signaling Technology), phospho-IRS-1 (Ser307; 1:1000, 2381, Cell Signaling Technology), Akt (1:1000, 4691, Cell Signaling Technology), phospho-Akt (Ser473, 1:1000, 9271, Cell Signaling Technology), glycogen synthase kinase (GSK)-3 $\beta$ (1:1000, 9315, Cell Signaling Technology), phospho-GSK-3 $\beta$ (Ser9, 1:1000, 9323, Cell Signaling Technology). All primary antibodies were diluted in $3 \%$ BSA in PBST. Proteins were made visible by enhanced chemiluminescence (Thermo Fisher Scientific).

ELISA assays used to quantify mouse insulin, TNF- $\alpha$ and IL- $1 \beta$ concentrations in the sera were obtained from Thermo Fisher Scientific according to the manufacturer's protocol.

\section{TaqMan real-time PCR microRNA array}

TaqMan Rodent MicroRNA Arrays (Thermo Fisher Scientific) were performed according to the manufacturer's instructions. Briefly, total RNA obtained from MSCexosomes was reverse-transcribed using TaqMan miRNA Megaplex reverse transcription kit (Thermo Fisher Scientific). Quantitative real-time PCR was performed on Applied Biosystems ViiA 7 system (Foster City, CA, USA). $\mathrm{C}_{\mathrm{t}}$ values $>35$ were considered to be below the detection level of the assay. The $\mathrm{C}_{\mathrm{t}}$ value of an endogenous control gene (U6 snRNA) was subtracted from the corresponding $C_{t}$ value for the target gene resulting in the $\Delta \mathrm{C}_{\mathrm{t}}$ value, which was used for relative quantification of miRNA expression.

Bioinformatics analysis Ingenuity Pathway Analysis (IPA) software (Qiagen, Hilden, Germany) was used for gene ontology (GO) analysis. IPA includes a manually annotated database of protein interactions and metabolic reactions obtained from the scientific literature. Genes that are putatively targeted by the selected miRNAs were imported into IPA and processed using the core analysis tool. Using the IPA knowledge base, networks of genes and miRNAs were built and 
graphically visualised as hubs (genes and miRNAs) and edges (the relationship between genes and genes/miRNAs).

Quantitative RT-PCR To verify the change of miRNAs expression in MSC-exosomes treated mice, total RNA was isolated from sciatic nerves of all groups using the miRNeasy Mini kit (Qiagen, Valencia, CA, USA). Reverse transcription was performed using miRNA reverse transcription kit (Applied Biosystems), the TaqMan real-time PCR reactions were performed using TaqMan Universal PCR Master Mix and TaqMan probes (Applied Biosystems). Relative quantities were calculated using the $2^{-\Delta \Delta \mathrm{C}_{\mathrm{t}}}$ method with U6 snRNA as the endogenous control.

Statistical analysis The data are presented as mean \pm SEM. Non-parametric one-way ANOVA followed by Tukey's post hoc test was performed for multiple groups comparisons. Two-tailed Student's $t$ test was performed for two-group comparisons. A value of $p<0.05$ was taken as significant.

\section{Results}

Characterisation of MSC-derived exosomes Ultrastructure and nanosize analysis demonstrated that MSC-exosomes had a cup-shaped canonical exosome morphology (Fig. 1a) with a mean size of $58.9 \pm 15.1 \mathrm{~nm}$ (electronic supplementary material [ESM] Fig. 1). Western blot analysis revealed that these exosomes expressed classical exosomal markers: CD9, CD63 and Alix (Fig. 1b) [28]. To determine the tissue distribution of exosomes, MSC-exosomes labelled with Texas Red were intravenously injected. Immunohistochemistry showed that

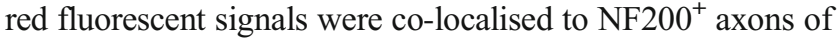
sciatic nerves and PGP9. $5^{+}$nerve fibres in footpad dermis $24 \mathrm{~h}$ after injection (Fig. 1c), while red fluorescent signals were not detected in mice without administration of the labelled MSCexosomes (Fig. 1c), suggesting that MSC-exosomes were internalised by peripheral nerves.

Treatment of diabetic mice with MSC-exosomes improves neurological outcomes At the age of 20 weeks, prior to the treatment, MCV and SCV were significantly lower in sciatic nerves of $d b / d b$ mice than those of non-diabetic $(d b / \mathrm{m})$ mice of the same age (Fig. 2b, c). The mechanical and thermal sensitivities were evaluated by von Frey test and radial heat plate test, respectively. $d b / d b$ mice exhibited a significant decrease in mechanical and thermal sensitivities compared with $d b / \mathrm{m}$ mice, indicating that $d b / d b$ mice at the age of 20 weeks have developed peripheral neuropathy (Fig. 2d, e). However, treatment of $d b / d b$ mice with MSC-exosomes significantly increased MCV by $16.8 \%$ and $30.3 \%$ and SCV by $17.3 \%$ and $24.9 \%$ at weeks 4 and 8 post treatment, respectively (Fig. 2b, c). Moreover, MSC-exosomes reduced mechanical response threshold and thermal response latency at week 4, 6, and 8 (Fig. 2d, e). Inherently, MSC-exosome treatment did not significantly alter thermal and mechanical sensitivities, MCV and SCV in $d b / \mathrm{m}$ mice compared with nontreated $d b / \mathrm{m}$ mice (ESM Fig. 2), suggesting that MSCexosomes do not affect sciatic nerve function in non-diabetic mice. These data suggest that MSC-exosomes specifically improve the neurological outcome of DPN.

MSC-exosome treatment ameliorates vascular dysfunction in peripheral nerve tissues Microvasculature dysfunction accompanies demyelination and a severe loss of myelinated axons in peripheral nerves, which are related to the progression of DPN [6]. Therefore, we measured regional blood flow in sciatic nerve and plantar skin with the laser Doppler image system. Regional blood flow perfusion in plantar skin and sciatic nerve tissues was dramatically decreased in $\mathrm{db} / \mathrm{db}$ mice compared with $d b / \mathrm{m}$ mice, whereas administration of MSCexosomes significantly retarded the reduced blood flow (Fig. $3 \mathrm{a}, \mathrm{b}, p<0.05)$. To quantify the density of plasma perfused microvessels, FITC-dextran was intravenously injected into the animals before euthanasia [29]. Consistent with blood flow results, treatment with MSC-exosomes significantly a

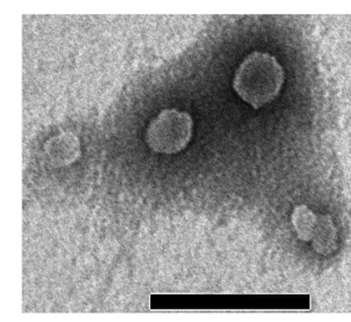

C
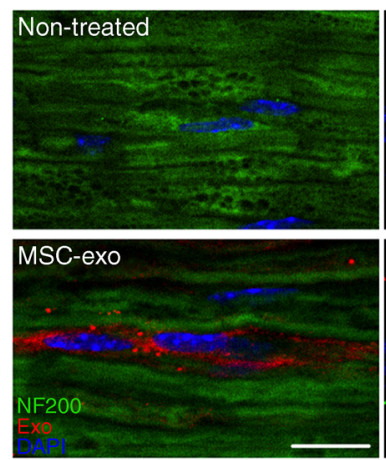

Sciatic nerve
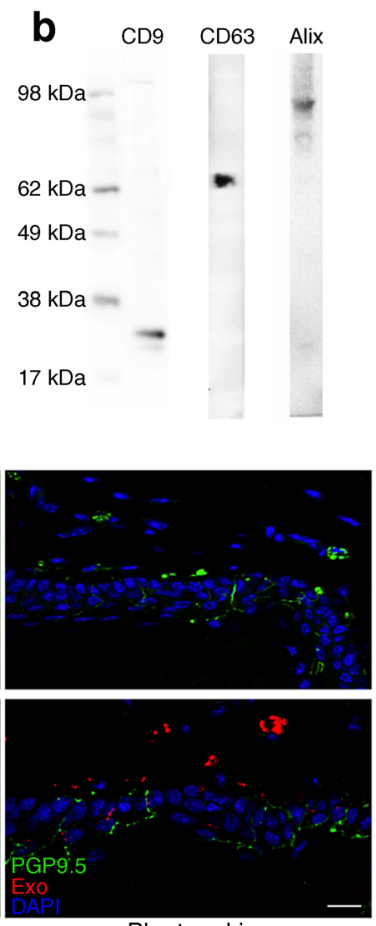

Plantar skin
Fig. 1 Exosome characterisation. (a) Transmission electron micrograph of MSC-exosomes. Round-shaped structures, 30-100 nm in size, were identified as exosomes. Scale bar, $200 \mathrm{~nm}$. (b) Representative western blot analysis for the exosome markers CD9, CD63 and Alix in MSCexosomes. (c) The distribution of Exo-Fect labelled MSC-exosomes (MSC-exo; red), together with NF200 and PGP9.5 (green). Scale bars, $20 \mu \mathrm{m}$ 
a
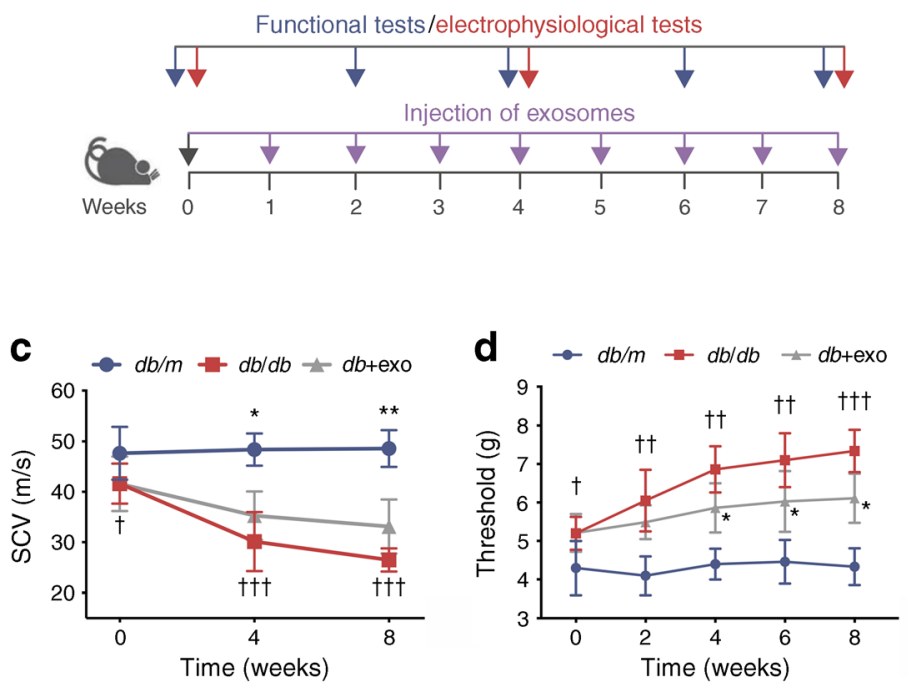
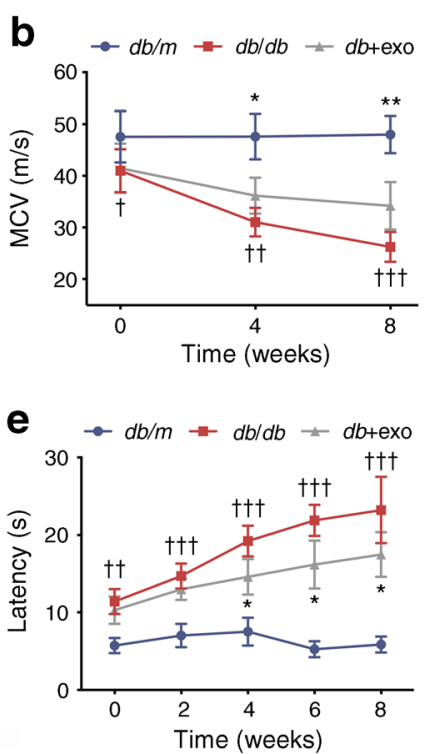

Fig. 2 MSC-exosomes improve neurological outcomes. (a) Schematic representation showing the treatment regimen of mice. (b, c) Before treatment (week 0), both MCV (b) and SCV (c) in the diabetic group were significantly decreased compared with the non-diabetic group of the same age. However, 8 weeks of treatment with MSC-exosomes significantly improved both MCV and SCV. Threshold to mechanical stimuli (d) and thermal response latency (e) in diabetic mice were decreased after MSCexosome treatment. Data are mean \pm SEM and were analysed by a oneway ANOVA with Tukey's post hoc test ( $n=8$ /group). ${ }^{\dagger} p<0.05$, ${ }^{\dagger \dagger} p<0.01,{ }^{\dagger \dagger} p<0.001 \mathrm{db} / \mathrm{db}$ vs $\mathrm{db} / \mathrm{m} ; * p<0.05$, ** $p<0.01 \mathrm{db} / \mathrm{db}$ vs $d b+$ exo. $d b / d b$, diabetic group treated with saline; $d b+$ exo, diabetic group treated with MSC-exosomes; $d b / \mathrm{m}$, non-diabetic group a
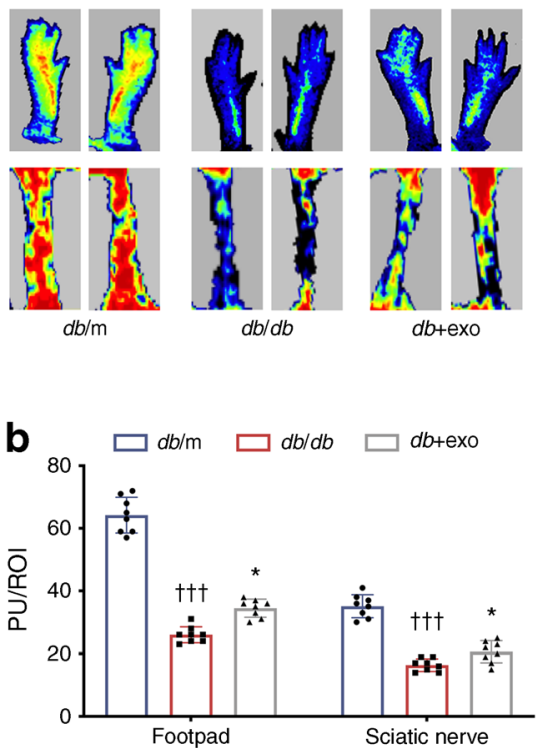

C

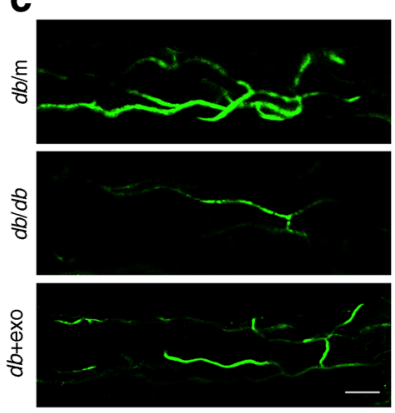

d

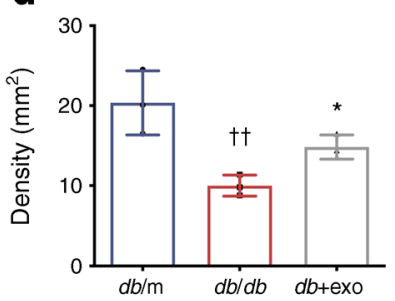

e

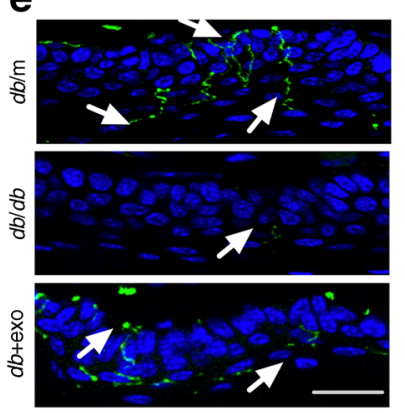

f

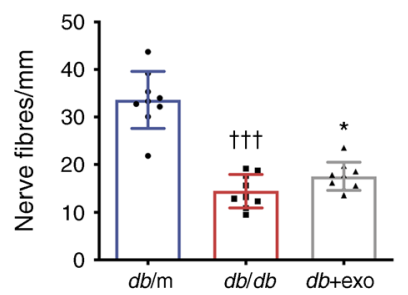

Fig. 3 MSC-exosome treatment increases blood flow perfusion in diabetic mice. (a) Representative laser Doppler images of the plantar skin (footpad; upper mages) and sciatic nerve (lower images) of mice. Flux within tissues was measured and perfusion signals are shown as different colours: blood flow from low to high is shown as blue-green-yelloworange-red. All of the mice were evaluated under the same experimental conditions. (b) Quantification of blood flow measurement results in (a), expressed in PU/ROI. $n=8 /$ group. (c, d) FITC-dextran perfused vessels from whole mounted sciatic nerves (c), and quantification of FITCdextran perfused vessel density (d). $n=3$ /group. Scale bar, $100 \mu \mathrm{m}$. (e, f) PGP9.5 staining of IENFs in hind paw plantar skin of all groups (e) and quantification of PGP9. $5^{+}$nerve fibre density (f). The epidermis showed a profound loss of PGP9. $5^{+}$IENF density in the $d b / d b$ group. Treatment with MSC-exosomes reversed the diabetes-induced loss of IENFs. $n=8$ / group. Scale bar, $50 \mu \mathrm{m}$. Data are mean \pm SEM and were analysed by one-way ANOVA with Tukey's post hoc test. ${ }^{\dagger \dagger} p<0.01,{ }^{\dagger \dagger} p<0.001 \mathrm{db} /$ $d b$ vs $d b / \mathrm{m} ; * p<0.05 d b / d b$ vs $d b+$ exo. $d b / d b$, diabetic group treated with saline; $d b+$ exo, diabetic group treated with MSC-exosomes; $d b / \mathrm{m}$, non-diabetic group 
increased FITC-perfused microvascular density in sciatic nerves compared with the saline treatment (Fig. 3c, d). Thus, our data suggest that treatment with MSC-exosomes improves vascular function.

\section{MSC-exosomes increase IENF density and axonal myelination}

The elevation of vascular perfusion is highly related to axonal regeneration in diabetic individuals [30]. We evaluated whether increased vascular perfusion was correlated with the alteration of distal nerve fibres. Measurement of PGP9. $5^{+}$ intraepidermal nerve fibre (IENF) density is a standard protocol to determine peripheral neuropathy [31]. At week 8 (28week-old), we found that $d b / d b$ mice displayed a significant reduction in PGP $9.5^{+}$nerve fibre density compared with that of $\mathrm{db} / \mathrm{m}$ mice, whereas administration of MSC-exosomes significantly increased PGP9. $5^{+}$IENF density compared with the saline treatment (Fig. 3e, f).

Next, we used toluidine blue myelin sheath staining to measure myelinated sciatic nerve fibres in diabetic mice
[32]. In non-diabetic $d b / \mathrm{m}$ mice, the nerve fibres appeared dense and myelinated, and the myelin sheaths were uniform and arranged as concentric rings (Fig. $4 \mathrm{a}$ ). In $d b / d b$ mice, the density of myelinated nerve fibres (Table 1) and the proportion of axons with a diameter of 5-6 $\mu \mathrm{m}$ were lower than those in $\mathrm{db} / \mathrm{m}$ mice, and large fibres ( $>6 \mu \mathrm{m}$ ) were absent (Fig. 4c). MSC-exosomes significantly increased the density and diameter of nerve fibres, and myelination, which led to reduced $g$ ratio compared with saline-treated $d b / d b$ mice (Fig. $4 \mathrm{~b}-\mathrm{d}$ ). In addition, double immunofluorescence analysis demonstrated a decrease in the myelin $\left(\mathrm{MBP}^{+}\right)$area $(-31.1 \%)$ and axon $\left(\mathrm{NF} 200^{+}\right)$area $(-34.2 \%)$ in sciatic nerve tissues of $d b / d b$ mice compared with $d b / \mathrm{m}$ mice. In contrast, MSC-exosome treatment increased the $\mathrm{MBP}^{+}$area by $7.9 \%$ and $\mathrm{NF}^{2} 00^{+}$area by $12.8 \%$, which was in line with the semi-thin section analysis (Fig. 4e, f).

MSC-derived exosomes do not affect hyperglycaemia and hyperlipidemia Glucose and oxidised lipoproteins interact
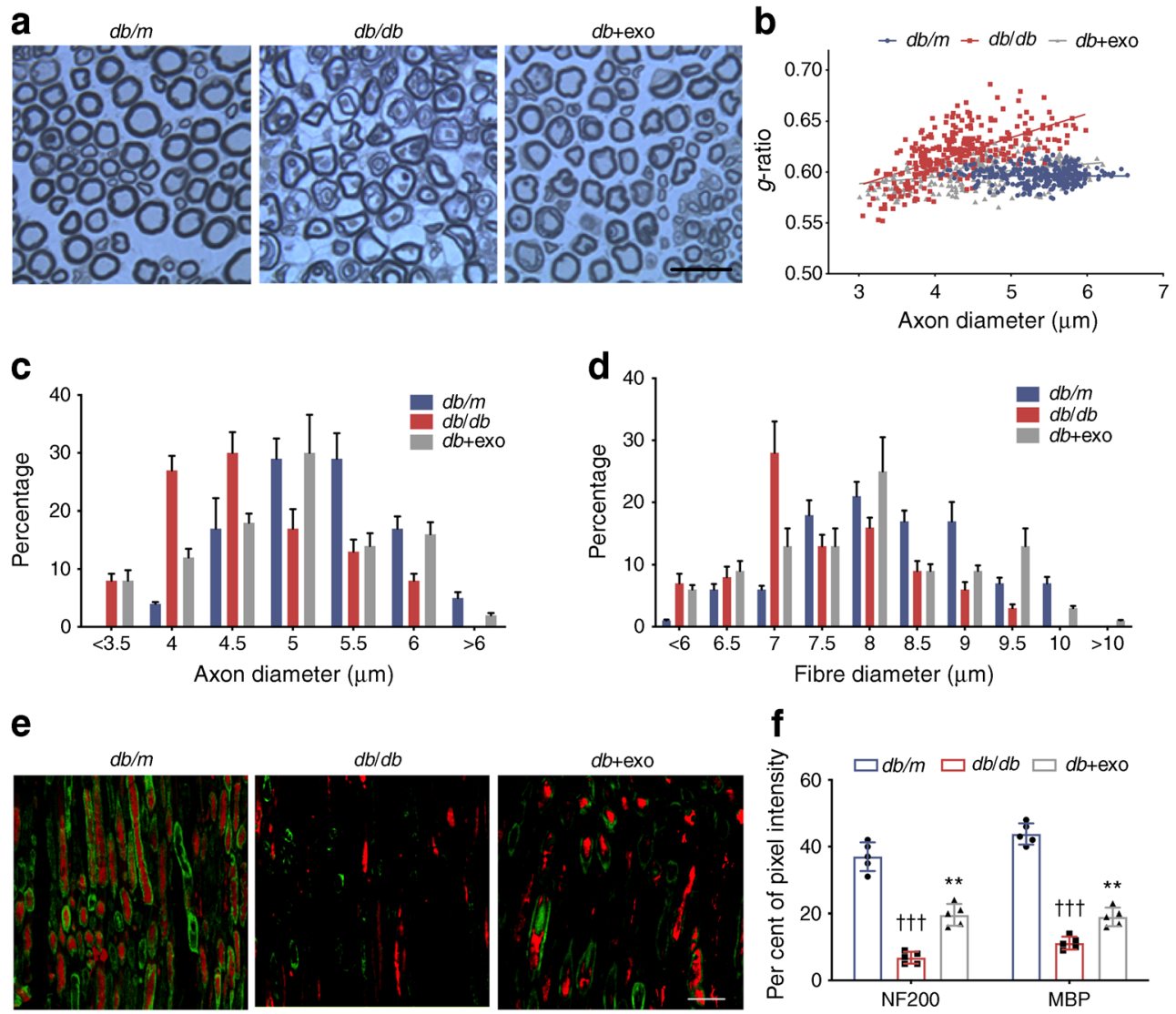

Fig. 4 Protective effect of MSC-exosomes on the myelinated axon fibres in the sciatic nerve of diabetic mice. (a) Semi-thin toluidine bluestained cross-sections of sciatic nerves; scale bar, $20 \mu \mathrm{m}$. (b) Scatter plot shows $g$-ratios of individual fibres as a function of the respective axon diameter. MSC-exosomes reduced the hypomyelination state of diabetic mice across all axon diameters but predominantly of the small and medium diameter axons. (c, d) Histograms showing the frequency distribution of the diameters of axons (c) and myelinated fibres (d). $n=8$ per group; $>300$ axons per animal. Representative immunofluorescence images (e) and quantification (f) of sciatic nerves labelled with NF200 (red) for visualising nerve fibres and MBP (green) for myelin sheath. Diabetic mice exhibited axonal and myelin damage. Administration of MSCexosomes reversed the nerve fibre demyelination. $n=5 /$ group. Scale bar, $50 \mu \mathrm{m}$. Data are mean \pm SEM and were analysed by one-way ANOVA with Tukey's post hoc test ( $n=5 /$ group). ${ }^{\dagger \dagger} p<0.001 \mathrm{db} / \mathrm{db}$ vs $d b / \mathrm{m}$; ** $p<0.01 d b / d b$ vs $d b+$ exo. $d b / d b$, diabetic group treated with saline; $d b+$ exo, diabetic group treated with MSC-exosomes; $d b / \mathrm{m}$, nondiabetic group 
Table 1 Effect of MSCexosomes on morphometric changes of myelinated sciatic nerves

\begin{tabular}{llll}
\hline Property & $d b / \mathrm{m}$ & $d b / d b$ & $d b+$ exo \\
\hline Fibre density $\left(/ \mathrm{mm}^{2}\right)$ & $13,060 \pm 1363$ & $9361 \pm 911^{\dagger \dagger \dagger}$ & $11,058 \pm 975^{* * * *}$ \\
Density of myelinated fibres $\left(/ \mathrm{mm}^{2}\right)$ & $10,420 \pm 792$ & $6829 \pm 364^{\dagger \dagger \dagger}$ & $7140 \pm 477^{* * * *}$ \\
Density of non-myelinated fibres $\left(/ \mathrm{mm}^{2}\right)$ & $2905 \pm 630$ & $664 \pm 496^{\dagger \dagger \dagger}$ & $922 \pm 552^{* *}$ \\
Fibre diameter $(\mu \mathrm{m})$ & $8.60 \pm 0.3$ & $7.25 \pm 0.13^{\dagger \dagger}$ & $8.08 \pm 0.13^{* *}$ \\
Axon diameter $(\mu \mathrm{m})$ & $5.00 \pm 0.11$ & $4.44 \pm 0.08^{\dagger \dagger}$ & $4.66 \pm 0.05^{* *}$ \\
Myelin thickness $(\mu \mathrm{m})$ & $1.71 \pm 0.05$ & $1.40 \pm 0.03^{\dagger \dagger}$ & $1.62 \pm 0.06^{*}$ \\
$g$-ratio & $0.59 \pm 0.01$ & $0.63 \pm 0.01^{\dagger}$ & $0.60 \pm 0.01^{*}$ \\
\hline
\end{tabular}

Values are mean \pm SEM; $n=5 /$ group

${ }^{\dagger} p<0.05,{ }^{\dagger \dagger} p<0.01,{ }^{\dagger \dagger} p<0.001 \mathrm{vs} d b / \mathrm{m}$ group $* * p<0.05$, ** $p<0.01$, *** $p<0.001 \mathrm{vs} d b / d b$ group

The $p$ values are calculated from two-tailed Student's $t$ test with various receptors on neurons and microvascular endothelial cells, disrupt mitochondrial metabolic pathways, and trigger inflammation [1]. We found that MSC-exosomes did not significantly affect levels of blood glucose and $\mathrm{HbA}_{1 \mathrm{c}}$ in diabetic $d b / d b$ mice compared with saline-treated diabetic mice, although both levels were significantly elevated compared with non-diabetic mice (Table 2). Similar results were also observed in lipid levels (Table 2).

Furthermore, we examined the effect of MSC-exosomes on insulin-associated signalling. We first measured serum and pancreatic insulin levels using ELISA. Serum and pancreatic insulin content were significantly increased (Table 2) and decreased (ESM Fig. 3), respectively, in the $d b / d b$ group compared with the $d b / \mathrm{m}$ group. Diabetic $d b / d b$ mice treated with MSC-exosomes did not exhibit significant alterations of insulin levels (Table 2, ESM Fig. 3). Additionally, the expression of molecules associated with insulin signalling, phosphorylated forms of IRS, Akt, and GSK-3 $\beta$, were not affected by MSC-exosome treatment, although they were significantly decreased in the sciatic nerve tissues of $d b / d b$ mice, compared with the $d b /$ m group (ESM Fig. 3). These results suggest that MSC-exosomes ameliorate DPN through mechanisms other than reducing glucose or lipid levels.

\section{MSC-derived exosomes suppress the inflammatory response of macrophages in peripheral nerves and circulation} Macrophages exert functions as key neuroinflammatory regulators that affect the neurovascular function of peripheral nerve tissues and facilitate the development of peripheral neuropathy [33]. We thus examined the activated macrophage accumulation by measuring the activated macrophages with an antibody against CD68 as well as the levels of inflammatory factors in myelinated axons. Immunostaining demonstrated that, in $\mathrm{db} / \mathrm{db}$ mice, activated $\mathrm{CD} 8^{+}$macrophage accumulation was significantly increased within the sciatic nerve (Fig. $5 \mathrm{a}, \mathrm{b})$. TNF- $\alpha$ immunoreactivity was negatively associated with NF200 and MBP immunoreactivity (Fig. 5a, c). ELISA data showed that $d b / d b$ mice exhibited a robust increase in serum levels of TNF- $\alpha$ and IL-1 $\beta$ (Fig. 6a, b). In contrast, treatment with MSC-exosomes significantly reduced the number of $\mathrm{CD}^{+} 8^{+}$macrophages and TNF- $\alpha$ expression in sciatic nerve tissues as well as decreased serum levels of TNF- $\alpha$ and IL-1 $\beta$ (Figs 5, 6a, b).

In addition, western blot analysis of sciatic nerve tissue demonstrated that $d b / d b$ mice had significantly increased levels of proinflammatory proteins TNF- $\alpha$, IL- $1 \beta$ and iNOS (markers of M1 macrophages) and substantial reduction of proteins of arginase-1, IL-10 and TGF- $\beta$ (markers of M2 macrophages) (Fig. 6c-e), compared with $d b / \mathrm{m}$ mice. In contrast, treatment of $d b / d b$ mice with MSC-exosomes reversed diabetes-increased M1 marker and diabetes-reduced M2 marker proteins compared with the saline treatment (Fig. 6c-e).

To examine the direct effect of MSC-exosomes on macrophage polarisation, intraperitoneal macrophages isolated from 20-week-old $d b / d b$ mice were incubated with MSCexosomes. We found that macrophages from $d b / d b$ mice expressed higher and lower levels of pro- and antiinflammatory genes, respectively, than the macrophages isolated from $d b / \mathrm{m}$ mice (Fig. 6f, g). However, MSCexosomes significantly reversed the expression pattern of these marker genes in diabetic macrophages (Fig. 6f, g), which was in line with our in vivo data.

MSC-exosome miRNAs are related to reduction of proinflammatory proteins in sciatic nerve tissue of $d b / d b$ mice We examined the miRNA profile within MSC-exosomes. Using the TaqMan MicroRNA array, a total of 215 miRNAs were detected in MSC-exosomes. The most highly enriched miRNAs include: let-7a, miR-23a, miR-125b, miR-92a, let7e, miR-17, miR-16, miR-142, miR-425, let-7d, miR-221, miR-19b, miR-24, miR-34a, miR-99b, miR-320, among others (Fig. 7a). Using quantitative (q)RT-PCR, we analysed exosomal enriched miRNAs in the sciatic nerve tissue and found that, compared with the saline treatment, the MSCexosome treatment significantly increased levels of these selected miRNAs in the sciatic nerve tissue of $d b / d b$ mice (Fig. 7c). Bioinformatics analysis showed that MSC- 
Table 2 Effect of MSCexosomes on hyperglycaemia, lipids and body weight

\begin{tabular}{|c|c|c|c|c|}
\hline Feature & & $d b / \mathrm{m}$ & $d b / d b$ & $d b+$ exo \\
\hline \multirow[t]{2}{*}{ Body weight (g) } & 0 weeks & $30.0 \pm 0.9$ & $53.3 \pm 6.6^{\dagger \dagger}$ & $54.3 \pm 6.5^{\dagger \dagger}$ \\
\hline & 8 weeks & $33.0 \pm 1.8$ & $54.5 \pm 7.8^{\dagger \dagger}$ & $53.2 \pm 8.3^{\dagger \dagger}$ \\
\hline \multirow[t]{2}{*}{ Blood glucose (mmol/l) } & 0 weeks & $7.2 \pm 0.9$ & $28.4 \pm 2.3^{\dagger \dagger \dagger}$ & $29.1 \pm 2.1^{\dagger \dagger \dagger}$ \\
\hline & 8 weeks & $7.1 \pm 0.9$ & $27.9 \pm 1.9^{\dagger \dagger \dagger}$ & $26.6 \pm 2.6^{\dagger \dagger \dagger}$ \\
\hline $\mathrm{HbA}_{1 \mathrm{c}}(\mathrm{mmol} / \mathrm{mol})$ & 0 weeks & $22.1 \pm 1.5$ & $89.1 \pm 15.1^{\dagger \dagger \dagger}$ & $85.8 \pm 11.6^{\dagger \dagger \dagger}$ \\
\hline $\mathrm{HbA}_{1 \mathrm{c}}(\%)$ & & $4.2 \pm 0.1$ & $10.3 \pm 2.1^{\dagger \dagger \dagger}$ & $10.0 \pm 1.1^{\dagger \dagger \dagger}$ \\
\hline $\mathrm{HbA}_{1 \mathrm{c}}(\mathrm{mmol} / \mathrm{mol})$ & 8 weeks & $22.6 \pm 3.1$ & $101.1 \pm 19.6^{\dagger \dagger \dagger}$ & $94.5 \pm 14.2^{\dagger \dagger \dagger}$ \\
\hline $\mathrm{HbA}_{1 \mathrm{c}}(\%)$ & & $4.4 \pm 0.3$ & $11.4 \pm 2.7^{\dagger \dagger \dagger}$ & $10.8 \pm 2.1^{\dagger \dagger \dagger}$ \\
\hline \multirow[t]{2}{*}{ Total cholesterol (mmol/l) } & 0 weeks & $2.2 \pm 0.2$ & $3.8 \pm 0.3^{\dagger \dagger \dagger}$ & $3.9 \pm 0.3^{\dagger \dagger \dagger}$ \\
\hline & 8 weeks & $2.3 \pm 0.2$ & $4.3 \pm 0.3^{\dagger \dagger \dagger}$ & $4.1 \pm 0.2^{\dagger \dagger \dagger}$ \\
\hline \multirow[t]{2}{*}{ Triacylglycerol (mmol/l) } & 0 weeks & $0.6 \pm 0.1$ & $0.9 \pm 0.1^{\dagger \dagger}$ & $0.9 \pm 0.1^{\dagger \dagger}$ \\
\hline & 8 weeks & $0.6 \pm 0.1$ & $1.0 \pm 0.1^{\dagger \dagger}$ & $1.0 \pm 0.1^{\dagger \dagger}$ \\
\hline \multirow[t]{2}{*}{ Serum insulin $(\mathrm{pmol} / \mathrm{l})$} & 0 weeks & $121.0 \pm 27.5$ & $315.0 \pm 44.0^{\dagger \dagger \dagger}$ & $307.0 \pm 34.4^{\dagger \dagger \dagger}$ \\
\hline & 8 weeks & $165.0 \pm 28.2$ & $330.0 \pm 24.0^{\dagger \dagger \dagger}$ & $319.0 \pm 31.5^{\dagger \dagger \dagger}$ \\
\hline
\end{tabular}

Values are mean \pm SEM; $n=8 /$ group

${ }^{\dagger \dagger} p<0.01,{ }^{\dagger \dagger} p<0.001 \mathrm{vs} d b / \mathrm{m}$ group

The $p$ values are from two-tailed Student's $t$ test exosome enriched miRNAs were highly involved in inflammation, cell cycle progression, non-insulin-dependent diabetes mellitus, apoptosis and diabetes (Fig. 7b). Intriguingly, network analysis with IPA showed that, among exosomal enriched miRNAs, miR-17, miR-23a and miR-125b targeted genes involved in the TLR4/NF-KB and receptor for advanced glycation end product (RAGE) signalling, which is wellknown to activate the inflammatory cascade and regulates macrophage phenotypes related to DPN (Fig. 7d) [34, 35]. Western blot analysis showed that protein levels of TLR4, IRAK1 and NF-KB p65 were significantly reduced in the sciatic nerve tissues of $d b / d b$ mice treated with MSCexosomes compared with those in $d b / d b$ mice treated with saline (Fig. 7e, f). Together, these data suggest that MSCexosomal miRNAs contribute to the downregulation of the TLR4/NF-KB signalling pathway. a

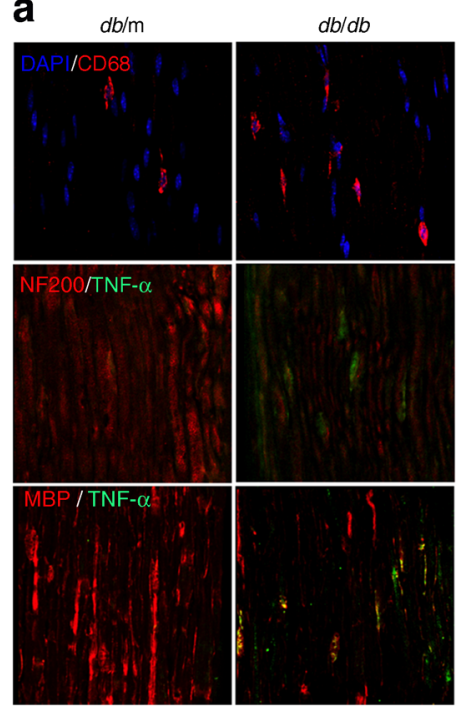

$d b+$ exo

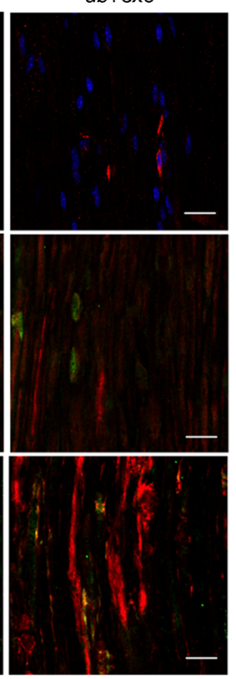

b
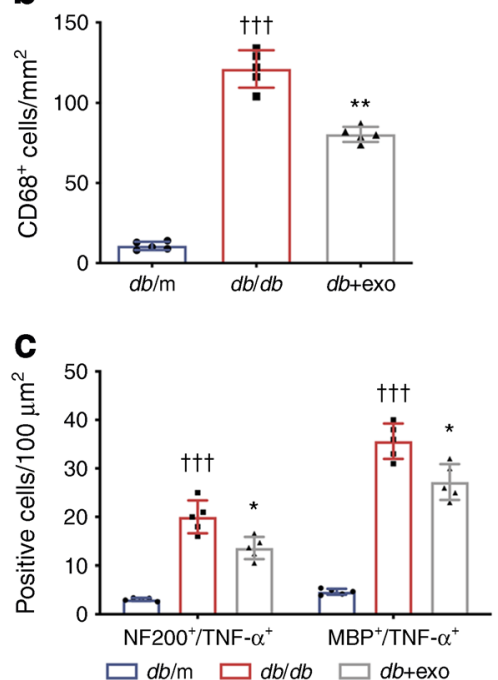

Fig. 5 MSC-exosomes suppress inflammatory response in peripheral nerves. (a) Representative immunofluorescence images of active macrophages $\left(\mathrm{CD}^{+} 8^{+}\right.$cells), TNF- $\alpha$, NF200 and MBP in sciatic nerves. (b) Quantitative data of $\mathrm{CD} 68^{+}$cells, as in (a). (c) Quantitative data showing co-localisation (yellow) of TNF- $\alpha$ with NF200 and MBP, as in (a). Nuclei are counterstained with DAPI (blue); scale bars, $20 \mu \mathrm{m}$. Data are mean \pm SEM and were analysed by one-way ANOVA with Tukey's post hoc test. ${ }^{\dagger \dagger} p<0.001 \mathrm{~d} b / \mathrm{db}$ vs $d b / \mathrm{m}$; * $p<0.05, * * p<0.01 \mathrm{db} / \mathrm{db}$ vs $d b+$ exo. $d b /$ $d b$, diabetic group treated with saline; $d b+$ exo, diabetic group treated with MSC-exosomes; $d b / \mathrm{m}$, non-diabetic group 


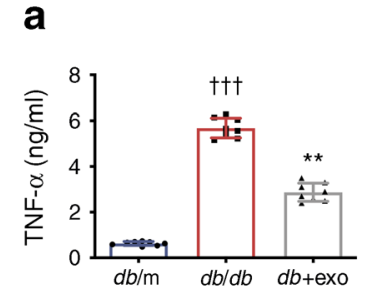

b

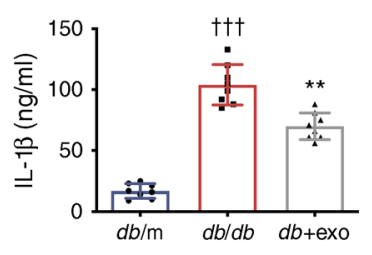

f

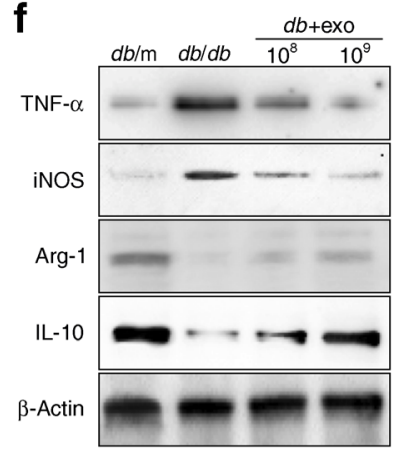

C

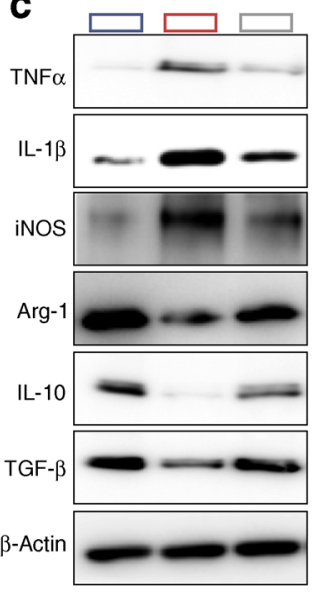

d

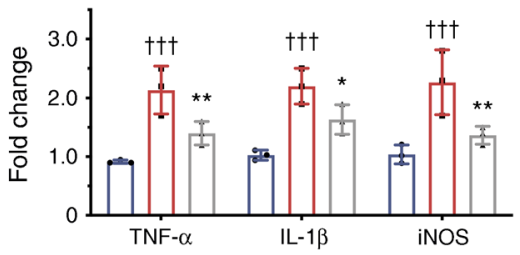

e

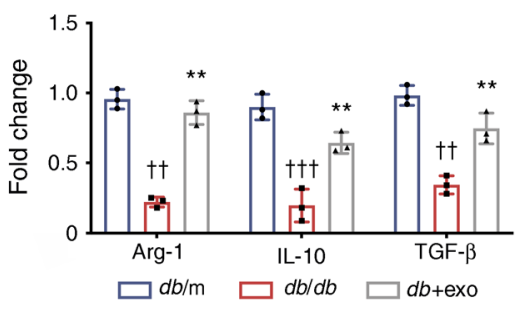

g

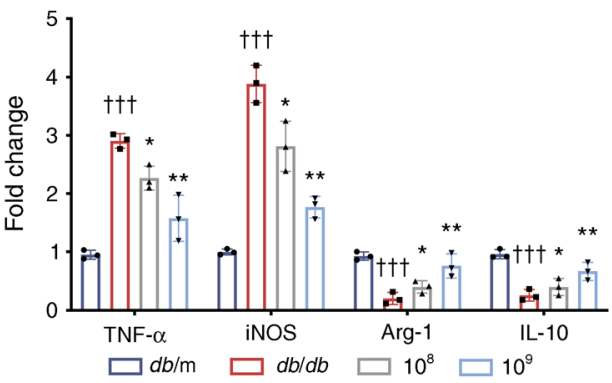

Fig. 6 MSC-exosomes reduce inflammatory response via regulating target gene expression. (a, b) MSC-exosome treatment reduced serum TNF- $\alpha$ (a) and IL-1 $\beta$ (b). (c) Representative images of western blot to assess levels of markers of M1 and M2 macrophages in sciatic nerves of mice treated with MSC-exosomes or saline in vivo. $n=8 /$ group. (d, e) Quantification of relative expression levels of markers of M1 and M2 macrophages, respectively, in sciatic nerves from all groups. $n=5 /$ group. (f, g) Representative images of western blot and the relative expression

levels of M1 and M2 markers in intraperitoneal macrophages isolated from $d b / d b$ mice that were treated with MSC-exosomes at a dose of $10^{8} /$ well, $10^{9} /$ well or PBS for $48 \mathrm{~h}$ in vitro. $n=3 /$ group. Data are mean \pm SEM and were analysed by one-way ANOVA with Tukey's post hoc test. ${ }^{\dagger} p<0.01,{ }^{\dagger \dagger} p<0.001 \mathrm{db} / \mathrm{db}$ vs $\mathrm{db} / \mathrm{m}$; * $p<0.05$, ** $p<0.01 \mathrm{db} / \mathrm{db}$ vs $d b+$ exo. $d b / d b$, diabetic group treated with saline (or PBS in f, g); $d b+$ exo, diabetic group treated with MSC-exosomes; $d b / \mathrm{m}$, non-diabetic group

\section{Discussion}

In the present study, we for the first time demonstrated that the treatment of diabetic mice with MSC-exosomes alleviates neurovascular dysfunction and axonal demyelination and improves neurological outcomes. Additionally, our data suggest that MSC-exosomal miRNAs may contribute to the observed therapeutic effect on DPN.

In DPN, microvascular disturbances were observed as basement membrane thickening and luminal size reduction [36]. Although the mechanism underlying microvascular disturbance has not been fully explored, it has been reported that chronic inflammation-induced local disruption of insulin signalling leads to micro- and macrovascular complications in diabetes [37, 38]. The breakdown of the endoneurial capillary-nerve barrier may impair endoneurial homeostasis, which allows toxic substances and immunoglobulins to enter the endoneurium, further deteriorating nerve fibres. Our data demonstrated that MSC-derived exosomes restored the blood

flow in peripheral tissues. MSCs have been shown to secrete neurotrophic and angiogenic factors such as fibroblast growth factor (FGF), vascular endothelial growth factor A (VEGFA), and nerve growth factor (NGF) to augment microcirculation support and to ameliorate DPN [16]. MSC-derived exosomes have been shown to regulate the biology of endothelial cells [39]. It is likely that MSC-derived exosomes carrying angiogenic and/or neurotrophic factors originating from parent cells underlie the function of exosomes. Whether MSC-exosomes have direct or specific effects on the biology of endothelial cells and Schwann cells remain to be determined.

Inflammation plays a pivotal role in DPN, and the inflammatory reaction and cytokines are key facilitators of this process. Our data demonstrated multiple structural and functional abnormalities in axons, vasculature and immune cells in diabetic mice. These abnormalities are highly correlated with increased levels of proinflammatory cytokines released by active resident and infiltrating macrophages in peripheral 

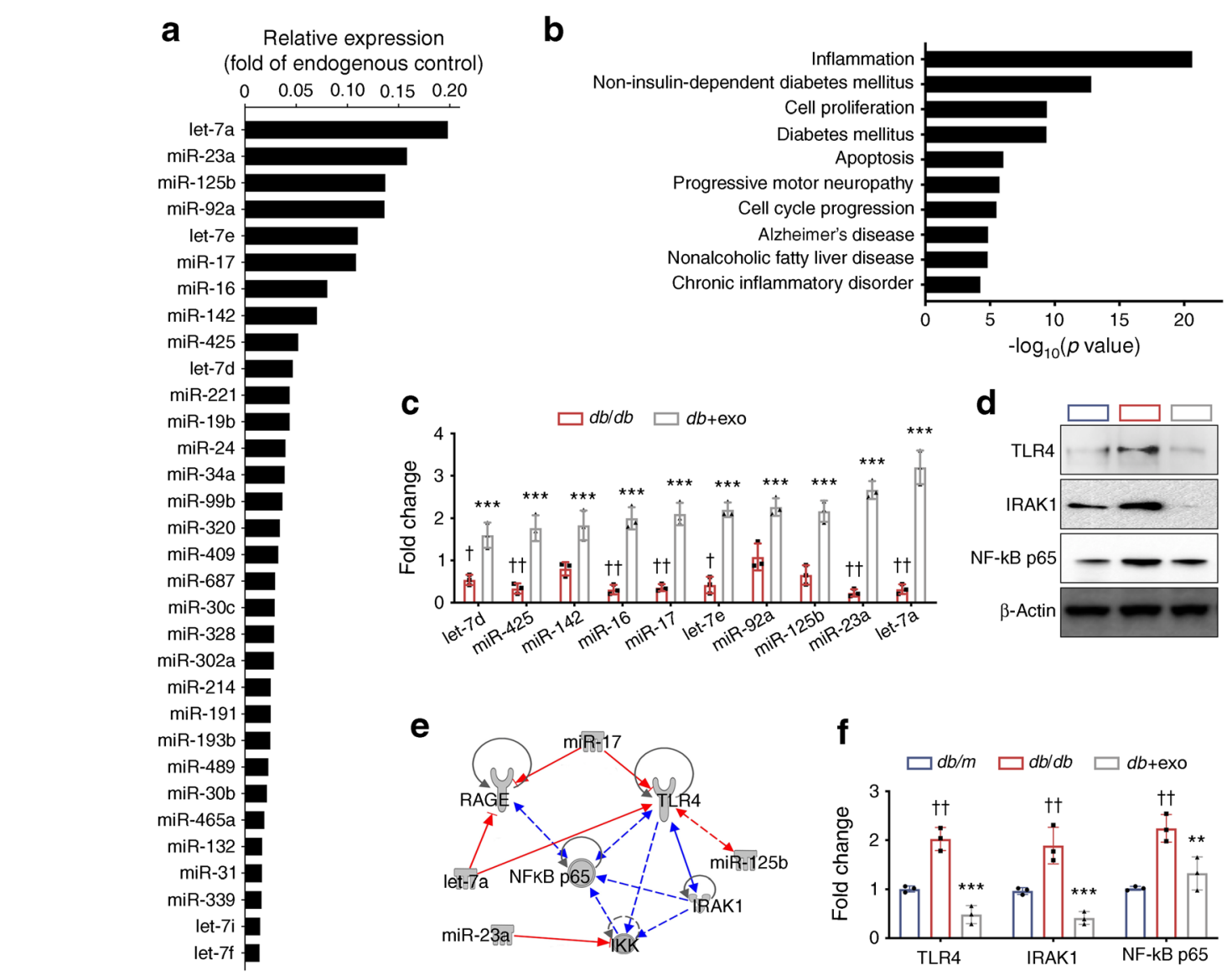

Fig. 7 miRNAs are involved in MSC-exosome-mediated macrophage polarisation. (a) Highly enriched miRNA content in MSC-exosomes. (b) Enriched biological processes for targeted genes of highly expressed miRNAs. (c) Relative miRNA expression in sciatic nerves from the $d b$ / $d b$ and $d b+$ exo groups, relative to the $d b /$ m group, set as 1 . (d) miRNAgene interactions were built into a bipartite network. Red lines indicate an inhibitory effect; the blue lines indicate a stimulatory effect; solid lines represent direct effects; dashed lines represent indirect effects. Western blot analysis (e) and quantitative data (f) of relative expression levels of TLR4, IRAK1 and NF-KB p65 in sciatic nerves of mice. Data are mean \pm SEM and were analysed by one-way ANOVA with Tukey's post hoc test ( $n=3$ /group). ${ }^{\dagger} p<0.05,{ }^{\dagger} p<0.01 \mathrm{db} / \mathrm{db}$ vs $d b / \mathrm{m} ; * * p<0.01, * * * p<$ $0.001 d b / d b$ vs $d b+$ exo. $d b / d b$, diabetic group treated with saline; $d b+$ exo, diabetic group treated with MSC-exosomes; $d b / \mathrm{m}$, non-diabetic group nerve tissues and the circulation [40]. We found that MSCexosomes significantly decreased levels of proinflammatory cytokines and inhibited the inflammatory response by converting inflammatory macrophages to M2 phenotype in sciatic nerves of diabetic mice. To examine the potential candidate molecules, we tested the miRNA cargo within MSCexosomes. Our study reveals that MSC-exosomes are enriched with miRNAs, including let-7a, miR-23a and miR-125b, among others, that synergistically target the TLR4/NF-KB signalling pathway. Growing evidence shows the involvement of TLR/NF- $\mathrm{KB}$ signalling activation in the pathogenesis of DPN $[25,41,42]$. Moreover, MSC-exosomes robustly reduced diabetes-augmented TLR4, IRAK1 and phospho-NF-kB p65 in the sciatic nerve. The reduction of inflammation by MSCexosomes improves neurovascular function [25]. Others have shown that MSC-exosomes inhibit macrophage activation by suppressing TLR signalling [43]. We and other groups have demonstrated that exosomal miRNAs mediate recipient cell function [23, 44]. Thus, the present finding that the inverse relationship between enrichment of exosomal miRNAs and reduction of proteins involved in the TLR signalling pathway in the recipient sciatic nerve tissue suggest that MSC-exosomal miRNAs contribute to the improvement of neurovascular function. Engineered exosomes carrying miRNAs or proteins have been reported to increase the efficacy of exosomes in the treatment of many diseases [45-48]. Future studies are warranted to investigate whether MSC-exosomes carrying elevated miRNAs that target genes that mediate inflammation and immuno-modulation may lead to therapies that further enhance neurological function in DPN.

DPN is a progressive disease, and the symptoms worsen over time. In parallel, compared with functional outcomes of diabetic mice measured at the age of 20 weeks, diabetic mice at 28 weeks exhibited significantly worse outcomes. Administration of MSC-exosomes ameliorated the neurovascular dysfunction and improved neurological 
outcomes at 28 weeks when the experiments were terminated. Interestingly, compared with functional outcomes at age 20 weeks of non-treated diabetic mice, we did not observe a significant improvement in neurological function measured at 28 weeks of diabetic mice treated with MSC-exosomes. These data suggest that MSC-exosomes probably protect early stages and the development of DPN. However, since we did not directly compare histopathological changes in diabetic mice before and after the MSC-exosome treatment, the possibility that MSC-exosomes reverse diabetes-induced neurovascular damage cannot be excluded.

In conclusion, our data demonstrate that the delivery of MSC-exosomes reduces the inflammatory response and promotes neurovascular remodelling and functional recovery of DPN in diabetic mice. Our observations provide new prospects for the use of MSC-exosomes as a potential treatment for patients with DPN.

Acknowledgements The authors thank J. Landschoot-Ward and Q.-e. Lu (Department of Neurology, Henry Ford Health System) for immunohistochemistry staining.

Data availability All data generated and analysed during this study are included in this published article.

Funding This work was supported by the National Institutes of Health National Institute of Diabetes and Digestive and Kidney Disease grant RO1 RDK102861A (XSL), American Heart Association Grant-in-Aid 14GRNT20460167 (XSL), and RO1 NS075156 (ZGZ).

Duality of interest The authors declare that there is no duality of interest associated with this manuscript.

Contribution statement XSL and BF designed the study, analysed and interpreted data, and composed the manuscript. BF, CL, AS, LW, WP, $\mathrm{RZ}, \mathrm{MC}$ and ZGZ conducted the experiments, acquired and analysed data and edited the manuscript. All authors have critically reviewed and approved the manuscript. XSL and ZGZ are the guarantors of this work and, as such, had full access to all of the data in the study and take responsibility for the integrity of the data and the accuracy of the data analysis.

\section{References}

1. Brownlee M (2001) Biochemistry and molecular cell biology of diabetic complications. Nature 414(6865):813-820. https://doi. org/10.1038/414813a

2. Said G (2007) Diabetic neuropathy-a review. Nat Clin Pract Neurol 3(6):331-340. https://doi.org/10.1038/ncpneuro0504

3. Callaghan BC, Little AA, Feldman EL, Hughes RA (2012) Enhanced glucose control for preventing and treating diabetic neuropathy. Cochrane Database Syst Rev 6:CD007543. https:// doi.org/10.1002/14651858.CD007543.pub2

4. Malik RA, Newrick PG, Sharma AK et al (1989) Microangiopathy in human diabetic neuropathy: relationship between capillary abnormalities and the severity of neuropathy. Diabetologia 32(2): 92-102. https://doi.org/10.1007/bf00505180
5. Watkins CJ, Johnson PC, Olafsen A, Beggs J (1992) Innervation of the vasa nervorum: changes in human diabetics. J Neuropathol Exp Neurol 51(6):612-629. https://doi.org/10.1097/00005072199211000-00006

6. Cameron NE, Eaton SEM, Cotter MA, Tesfaye S (2001) Vascular factors and metabolic interactions in the pathogenesis of diabetic neuropathy. Diabetologia 44(11):1973-1988. https://doi.org/10. 1007/s001250100001

7. Cameron NE, Cotter MA (1997) Metabolic and vascular factors in the pathogenesis of diabetic neuropathy. Diabetes 46(Suppl 2):S31S37

8. Hinder LM, Murdock BJ, Park M et al (2018) Transcriptional networks of progressive diabetic peripheral neuropathy in the $d b /$ $d b$ mouse model of type 2 diabetes: an inflammatory story. Exp Neurol 305:33-43. https://doi.org/10.1016/j.expneurol.2018.03. 011

9. Austin PJ, Moalem-Taylor G (2010) The neuro-immune balance in neuropathic pain: involvement of inflammatory immune cells, immune-like glial cells and cytokines. J Neuroimmunol 229(1-2): 26-50. https://doi.org/10.1016/j.jneuroim.2010.08.013

10. Zhou J, Zhou S (2014) Inflammation: therapeutic targets for diabetic neuropathy. Mol Neurobiol 49(1):536-546. https://doi.org/10. 1007/s12035-013-8537-0

11. Negi G, Kumar A, Sharma SS (2011) Melatonin modulates neuroinflammation and oxidative stress in experimental diabetic neuropathy: effects on NF-KB and Nrf2 cascades. J Pineal Res 50(2):124 131. https://doi.org/10.1111/j.1600-079X.2010.00821.x

12. Katakowski M, Buller B, Zheng X et al (2013) Exosomes from marrow stromal cells expressing miR-146b inhibit glioma growth. Cancer Lett 335(1):201-204. https://doi.org/10.1016/j.canlet.2013. 02.019

13. Han JW, Choi D, Lee MY, Huh YH, Yoon YS (2016) Bone marrow-derived mesenchymal stem cells improve diabetic neuropathy by direct modulation of both angiogenesis and myelination in peripheral nerves. Cell Transplant 25(2):313-326. https://doi.org/ 10.3727/096368915X688209

14. Siniscalco D, Giordano C, Galderisi U et al (2010) Intra-brain microinjection of human mesenchymal stem cells decreases allodynia in neuropathic mice. Cell Mol Life Sci 67(4):655-669. https://doi.org/10.1007/s00018-009-0202-4

15. Waterman RS, Morgenweck J, Nossaman BD, Scandurro AE, Scandurro SA, Betancourt AM (2012) Anti-inflammatory mesenchymal stem cells (MSC2) attenuate symptoms of painful diabetic peripheral neuropathy. Stem Cells Transl Med 1(7):557-565. https://doi.org/10.5966/sctm.2012-0025

16. Shibata T, Naruse K, Kamiya H et al (2008) Transplantation of bone marrow-derived mesenchymal stem cells improves diabetic polyneuropathy in rats. Diabetes 57(11):3099-3107. https://doi. org/10.2337/db08-0031

17. Zurita M, Vaquero J, Oya S, Bonilla C, Aguayo C (2007) Neurotrophic Schwann-cell factors induce neural differentiation of bone marrow stromal cells. Neuroreport 18(16):1713-1717. https://doi.org/10.1097/WNR.0b013e3282f0d3b0

18. Jeong JO, Han JW, Kim JM et al (2011) Malignant tumor formation after transplantation of short-term cultured bone marrow mesenchymal stem cells in experimental myocardial infarction and diabetic neuropathy. Circ Res 108(11):1340-1347. https://doi.org/10.1161/ CIRCRESAHA.110.239848

19. van Niel G, D'Angelo G, Raposo G (2018) Shedding light on the cell biology of extracellular vesicles. Nat Rev Mol Cell Biol 19(4): 213-228. https://doi.org/10.1038/nrm.2017.125

20. Zhang ZG, Buller B, Chopp M (2019) Exosomes - beyond stem cells for restorative therapy in stroke and neurological injury. Nat Rev Neurol 15(4):193-203. https://doi.org/10.1038/s41582-0180126-4 
21. Alvarez-Erviti L, Seow Y, Yin H, Betts C, Lakhal S, Wood MJ (2011) Delivery of siRNA to the mouse brain by systemic injection of targeted exosomes. Nat Biotechnol 29(4):341-345. https://doi. org/10.1038/nbt.1807

22. Furuta T, Miyaki S, Ishitobi H et al (2016) Mesenchymal stem cellderived exosomes promote fracture healing in a mouse model. Stem Cells Transl Med 5(12):1620-1630. https://doi.org/10.5966/sctm. 2015-0285

23. Zhang Y, Chopp M, Liu XS et al (2017) Exosomes derived from mesenchymal stromal cells promote axonal growth of cortical neurons. Mol Neurobiol 54(4):2659-2673. https://doi.org/10. 1007/s12035-016-9851-0

24. Obrosova IG, Ilnytska O, Lyzogubov VV et al (2007) High-fat diet induced neuropathy of pre-diabetes and obesity: effects of "healthy" diet and aldose reductase inhibition. Diabetes 56(10):2598-2608. https://doi.org/10.2337/db06-1176

25. Liu XS, Fan B, Szalad A et al (2017) MicroRNA-146a mimics reduce the peripheral neuropathy in type II diabetic mice. Diabetes. https://doi.org/10.2337/db16-1182

26. Chaplan SR, Bach FW, Pogrel JW, Chung JM, Yaksh TL (1994) Quantitative assessment of tactile allodynia in the rat paw. J Neurosci Methods 53(1):55-63. https://doi.org/10.1016/01650270(94)90144-9

27. Lu M, Varley AW (2013) Harvest and culture of mouse peritoneal macrophages. Bio-protocol 3(22):e976. https://doi.org/10.21769/ BioProtoc.976

28. Wu X, Gao Y, Xu L et al (2017) Exosomes from high glucosetreated glomerular endothelial cells trigger the epithelialmesenchymal transition and dysfunction of podocytes. Sci Rep 7(1):9371. https://doi.org/10.1038/s41598-017-09907-6

29. Rajendran P, Rengarajan T, Thangavel J et al (2013) The vascular endothelium and human diseases. Int J Biol Sci 9(10):1057-1069. https://doi.org/10.7150/ijbs. 7502

30. Goncalves NP, Vaegter CB, Andersen H, Ostergaard L, Calcutt NA, Jensen TS (2017) Schwann cell interactions with axons and microvessels in diabetic neuropathy. Nat Rev Neurol 13(3):135147. https://doi.org/10.1038/nrneurol.2016.201

31. Lauria G, Cornblath DR, Johansson O et al (2005) EFNS guidelines on the use of skin biopsy in the diagnosis of peripheral neuropathy. Eur J Neurol 12(10):747-758. https://doi.org/10.1111/j.1468-1331. 2005.01260.x

32. Di Scipio F, Raimondo S, Tos P, Geuna S (2008) A simple protocol for paraffin-embedded myelin sheath staining with osmium tetroxide for light microscope observation. Microsc Res Tech 71(7):497502. https://doi.org/10.1002/jemt.20577

33. Callaghan BC, Cheng HT, Stables CL, Smith AL, Feldman EL (2012) Diabetic neuropathy: clinical manifestations and current treatments. Lancet Neurol 11(6):521-534. https://doi.org/10.1016/ S1474-4422(12)70065-0

34. Lawrence T, Fong C (2010) The resolution of inflammation: antiinflammatory roles for NF-KB. Int J Biochem Cell Biol 42(4):519523. https://doi.org/10.1016/j.biocel.2009.12.016

35. Toth C, Martinez J, Zochodne DW (2007) RAGE, diabetes, and the nervous system. Curr Mol Med 7(8):766-776. https://doi.org/10. 2174/156652407783220705
36. Powell HC, Rosoff J, Myers RR (1985) Microangiopathy in human diabetic neuropathy. Acta Neuropathol 68(4):295-305. https://doi. org/10.1007/bf00690832

37. Shoelson SE, Lee J, Goldfine AB (2006) Inflammation and insulin resistance. J Clin Invest 116(7):1793-1801. https://doi.org/10.1172/ JCI29069

38. Reddy MA, Jin W, Villeneuve L et al (2012) Pro-inflammatory role of microrna-200 in vascular smooth muscle cells from diabetic mice. Arterioscler Thromb Vasc Biol 32(3):721-729. https://doi. org/10.1161/ATVBAHA.111.241109

39. Gong M, Yu B, Wang J et al (2017) Mesenchymal stem cells release exosomes that transfer miRNAs to endothelial cells and promote angiogenesis. Oncotarget 8(28):45200-45212. https://doi.org/10. 18632/oncotarget.16778

40. Peters CM, Jimenez-Andrade JM, Jonas BM et al (2007) Intravenous paclitaxel administration in the rat induces a peripheral sensory neuropathy characterized by macrophage infiltration and injury to sensory neurons and their supporting cells. Exp Neurol 203(1):42-54. https://doi.org/10.1016/j.expneurol.2006.07.022

41. Zhu T, Meng Q, Ji J, Lou X, Zhang L (2015) Toll-like receptor 4 and tumor necrosis factor- $\alpha$ as diagnostic biomarkers for diabetic peripheral neuropathy. Neurosci Lett 585:28-32. https://doi.org/10. 1016/j.neulet.2014.11.020

42. Elzinga S, Murdock BJ, Guo K et al (2019) Toll-like receptors and inflammation in metabolic neuropathy; a role in early versus late disease? Exp Neurol 320:112967. https://doi.org/10.1016/j. expneurol.2019.112967

43. Phinney DG, Di Giuseppe M, Njah J et al (2015) Mesenchymal stem cells use extracellular vesicles to outsource mitophagy and shuttle microRNAs. Nat Commun 6:8472. https://doi.org/10. 1038/ncomms9472

44. Zhang J, Li S, Li L et al (2015) Exosome and exosomal microRNA: trafficking, sorting, and function. Genomics Proteomics Bioinformatics 13(1):17-24. https://doi.org/10.1016/j.gpb.2015. 02.001

45. Xin H, Katakowski M, Wang F et al (2017) MicroRNA cluster miR-17-92 cluster in exosomes enhance neuroplasticity and functional recovery after stroke in rats. Stroke 48(3):747-753. https:// doi.org/10.1161/STROKEAHA.116.015204

46. Monaco F, Gaetani S, Alessandrini F et al (2019) Exosomal transfer of miR-126 promotes the anti-tumour response in malignant mesothelioma: role of miR-126 in cancer-stroma communication. Cancer Lett 463:27-36. https://doi.org/10.1016/j.canlet.2019.08. 001

47. Saravanan PB, Vasu S, Yoshimatsu G et al (2019) Differential expression and release of exosomal miRNAs by human islets under inflammatory and hypoxic stress. Diabetologia. 62(10):1901-1914. https://doi.org/10.1007/s00125-019-4950-x

48. Yuan Z, Petree JR, Lee FE et al (2019) Macrophages exposed to HIV viral protein disrupt lung epithelial cell integrity and mitochondrial bioenergetics via exosomal microRNA shuttling. Cell Death Dis 10(8):580. https://doi.org/10.1038/s41419-019-1803-y

Publisher's note Springer Nature remains neutral with regard to jurisdictional claims in published maps and institutional affiliations. 